\title{
Prevalence of tuberculosis in children of sputum positive adult of pulmonary tuberculosis living in same household
}

\author{
Beck $\mathbf{P}^{1}$, Kurrey VK ${ }^{2}$, Dawale $\mathbf{P}^{3}$ \\ ${ }^{1}$ Dr P. Beck, Associate Professor, Pt JNM Medical College, Raipur, ${ }^{2}$ Dr Virendra K. Kurrey, Associate Professor, Pt \\ JNM Medical College, Raipur, ${ }^{3}$ Dr Prafull Dawale, Associate Professor, Government Medical College Rajnandgaon, \\ CG, India
}

Address for correspondence: Dr Virendra K. Kurrey, Email: virendra_kurrey@yahoo.com

\begin{abstract}
Introduction: Mortality due to tuberculosis can be prevented with proper screening, diagnosis and treatment. Present study is proposed to propagate screening of all children in families of all adult with sputum positive for AFB by relevant test available locally. This will help in early detection childhood infection. Objective of this study was to identify the prevalence of tuberculosis in children of sputum positive adult of pulmonary tuberculosis living in same household. If the findings are statistically significant routine screening should be recommended as part of RNTCP. Method: Prospective, hospital plus community based study during a period of February 20013 to November 20014, inclusion criteria includes all children 5-14 year, should have contact with sputum positive adult, exclusion criteria - children who treated with antitubercular, TB with concurrent immunosupression, Detail history, clinical examination, and investigation done to find out tubercular infection or disease. Result: We observed that among 218 children $40 \%$ children had tubercular infection out of which 23 children had tubercular disease. Data of different parameter is observed and analyzed which is found statistically significant. Conclusion: This study argue strongly in favours of routine screening of all children in contact with sputum positive adult of PTB and identify this group of child at high risk who should be screened on a priority basis if there of resources and time to screen all family contact.
\end{abstract}

Keyword: Childhood Tuberculosis, Extrapulmonary Tuberculosis, RNTCP, Antitubercular drugs

\section{Introduction}

Currently in India more than thousand people die from tuberculosis but this death can be prevented with early anticipation, screening. Tuberculosis is one of neglected health crisis and is out of control in many part of world. High incidence of risk of infection is particularly among close contact of infectious patient, which is usually family member. It is supposed that transmission of tuberculosis to children is typically from parent to children through house hold contact $[1,2,3]$. One tuberculosis patient can multiply mycobacterium tuberculosis to other 10 person who may living in same house. Childhood tuberculosis is rising because of persisting inability to confirm the diagnosis resulting larger number of children dies of undiagnosed tuberculosis [4,5,6,7]. Diagnosis of tuberculosis in children poses technical and operational challenges because of vague and non specific symptomatology, difficult in getting sputum sample for testing. The

\footnotetext{
Manuscript received: $5^{\text {th }}$ June 2015

Reviewed: $18^{\text {th }}$ June 2015

Author Corrected: $4^{\text {th }}$ July 2015

Accepted for Publication: $16^{\text {th }}$ July 2015
}

present study is proposed to screen all children in family of adult with sputum positive for AFB by detailed history, clinical examination and relevant test available locally. This will also help to identify incidence of tuberculosis in children living with sputum positive TB cases. The finding may also help to plan and include recommendation in RNTCP for routine assessment of such children, if finding found to be statistically significant.

\section{Material and Methods}

This Prospective, hospital plus community based study was conducted during a period of February 20013 to November 20014 total 218 children who were in contact with sputum positive adult of tuberculosis registered with RNTCP include in study. The study was initiated with approval of institutional ethical committee and written informed consent of parent was obtained prior to enrolment and to conduct various invasive procedure and investigation. 
Selection of cases: children 5-14 year, should have contact with sputum positive adult and registered under RNTCP, children from institution and also from community of sputum positive adult.

Exclusion criteria: children who had been previously treated with antitubercular, TB with concurrent immunosupression and sputum negative contact and extrapulmonary tuberculosis.

All 218 children between 1-14 year were undergone for Detail history which include prolong fever, cough more than 2 weeks, failure to gain weight, loss of appetite, decline in weight and symptom of extrapulmonary tuberculosis such as lymphadenopathy, seizure, abdominal pain were recorded. Socioeconomic status was determined with the help of kuppuswamy classification to categorize families as upper, middle and lower economic group [8]. Assessment of nutritional status was done by various anthropometric measurements.

Clinical examination and investigation done to find out tubercular infection or disease i.e mantoux test carried out with 1 TU consider positive if induration more than $10 \mathrm{~mm}$, this patient further investigate for chest $\mathrm{x}$-ray and age matched technique to take sample for sputum examination. Few investigation were needed on basis of indication i.e. FNAC, lumber puncture, lymph node biopsy, pleural fluid microscopy $[9,10]$.

The observation were depicted in tabulated form and correlation with tuberculin test was studies with various factor the data were subjected to statistically analyzed by mean of chi-square test and probability value (' $\mathrm{p}$ ' value) determined after applying student ' $t$ ' test.

\section{Result}

Table 1 showed among 218 children of age up to 14 year, 94 children (43\%) belongs to age group < 5years, 124 children $68(31 \%)$ belong to age group between $5-10$ year and rest 56 children (26\%) belongs to 11-14 years age group. Positive tuberculin test reaction was more in 5-14 year age group (47\%) as compared to <5 years age group in which only $32 \%$ were tuberculin positive. The male (55\%), female (45\%) ratio was approximately 1.2:1. The tuberculin had no significant correlation with sex of child.

\begin{tabular}{|l|l|l|l|l|l|l|l|l|}
\hline Table 1: sex wise distribution of case \\
\hline Sex & Number of cases & Percentage \\
\hline Male & 120 & 55 & 45 \\
\hline Female & 98 & 40 & \multicolumn{5}{|c|}{$\mathbf{6 - 1 0 m m}$} & Nom \\
\hline Age wise distribution of cases and its correlation with tuberculin test \\
\hline \\
\hline
\end{tabular}

Table 2 showed Among 218 children most children have varying degree of malnutrition and on 50\% had normal nutrition. On correlation of nutritional status of children with tuberculin reaction it was noted that all type of reaction were recorded in various degree of malnutrition. It was particularly noted that positive reaction were more in children with severe malnutrition (54\%) as compared to normally nourished and mildly malnourished children (38\%).

Table 2 showed Tuberculin positivity is affected by socioeconomic status of children. Among 218 children majority of them belongs to lower class $(65 \%)$ and rest belong to upper and middle class $(35 \%)$. Incidence of positive tuberculin reaction is more in lower socioeconomic group. 
Table 2: Distribution of cases according to socioeconomic status \& its correlation with tuberculin reaction

\begin{tabular}{|c|c|c|c|c|c|c|c|c|}
\hline \multirow{3}{*}{$\begin{array}{l}\text { Socioeconomic } \\
\text { status }\end{array}$} & \multirow{3}{*}{$\begin{array}{c}\text { No. of cases(n- } \\
218) \\
\end{array}$} & \multirow{3}{*}{$\begin{array}{c}\text { Percenta } \\
\text { ge }\end{array}$} & \multicolumn{6}{|c|}{ Tuberculin reaction } \\
\hline & & & \multicolumn{2}{|c|}{$1-5 \mathrm{~mm}$} & \multicolumn{2}{|c|}{ 6-10mm } & \multicolumn{2}{|c|}{$>10 \mathrm{~mm}$} \\
\hline & & & No. & $\%$ & No. & $\%$ & No. & $\%$ \\
\hline Upper class & 6 & 3 & 4 & 67 & 0 & 0 & 2 & 33 \\
\hline Middle class & 70 & 32 & 42 & 60 & 4 & 6 & 24 & 34 \\
\hline Lower class & 142 & 65 & 72 & 51 & 8 & 6 & 62 & 43 \\
\hline Total & 218 & & 118 & & 12 & & 88 & \\
\hline \multicolumn{9}{|c|}{$\mathrm{X}^{2}-4.43$ p $<0.05$ (significant) } \\
\hline \multicolumn{9}{|c|}{ Distribution of cases according to nutritional status \& its correlation with tuberculin reaction } \\
\hline Nutritional status & & & \multicolumn{2}{|c|}{$1-5 \mathrm{~mm}$} & \multicolumn{2}{|c|}{ 6-10mm } & \multicolumn{2}{|c|}{$>10 \mathrm{~mm}$} \\
\hline Normal nutrition & 110 & 50 & 66 & 60 & 4 & 4 & 40 & 36 \\
\hline Mild malnutrition & 78 & 36 & 42 & 54 & 4 & 15 & 32 & 41 \\
\hline $\begin{array}{l}\text { Severe } \\
\text { malnutrition }\end{array}$ & 30 & 14 & 10 & 33 & 4 & 13 & 168 & 54 \\
\hline Total & 218 & & 118 & & & & 8 & \\
\hline
\end{tabular}

Table 3 showed 204 children were vaccinated with BCG. In BCG vaccinated children 39\% had tuberculin reaction positive while non vaccinated had $57 \%$ tuberculin positivity.

Table 3 showed among study group positive tuberculin reaction were seen in $88(40 \%)$ children out of whom $48 \%$ showed $10-15 \mathrm{~mm}$ induration, $18 \%$ showed $16-20 \mathrm{~mm}$ and $>20 \mathrm{~mm}$ seen in $34 \%$ of children. We observed that tuberculin reaction of $>10 \mathrm{~mm}$ induration were more common in children who had history compatible with tuberculosis, raised ESR, lympocytosis, abnormal chest X ray , FNAC, CSF suggestive of tubercular disease. Tuberculin reaction of $>10 \mathrm{~mm}$ induration in children with supportive clinical and investigation finding can be diagnostic criteria for presence of active tuberculosis.

\begin{tabular}{|c|c|c|c|c|c|c|c|}
\hline \multicolumn{8}{|c|}{ Table 3: distribution of cases according to degree of tuberculin reactivity } \\
\hline Tuberculin reaction & $\begin{array}{l}\text { Number of } \\
\text { cases(n-218) }\end{array}$ & Perc & & & & & \\
\hline Negative (1-5mm) & 118 & 54 & & & & & \\
\hline Doubtful(6-10mm) & 12 & 6 & & & & & \\
\hline Positive (10-15mm) & 42 & 16 & & & & & \\
\hline Positive (16-20mm) & 16 & 7 & & & & & \\
\hline Strongly positive (>20mm) & 30 & 14 & & & & & \\
\hline \multicolumn{8}{|c|}{ Correlation of tuberculin reaction with BCG vaccination } \\
\hline \multirow[t]{3}{*}{ BCG vaccination } & \multirow[t]{3}{*}{ No. of cases } & & & & & & \\
\hline & & \multicolumn{2}{|c|}{$1-5 \mathrm{~mm}$} & \multicolumn{2}{|c|}{ 6-10mm } & \multicolumn{2}{|c|}{$>10 \mathrm{~mm}$} \\
\hline & & No. & $\%$ & No. & $\%$ & No. & $\%$ \\
\hline BCG scar present & 204 & 112 & 55 & 12 & 6 & 80 & 39 \\
\hline BCG scar absent & 14 & 6 & 43 & 0 & 0 & 8 & 57 \\
\hline \multicolumn{8}{|c|}{$X^{2}-3.85 p<0.05$ (significant) } \\
\hline
\end{tabular}

Table 4 showed among 218 children 68 children were exposed to passive smoking and 150 were not exposed. Among exposed children $38 \%$ children had positive tuberculin test. $41 \%$ children showed positive reaction among non exposed. 
Table 4: Showing distribution of cases according to exposure to passive smoking \& its correlation of tuberculin reaction

\begin{tabular}{|c|c|c|c|c|c|c|c|}
\hline \multirow[t]{3}{*}{ Exposure } & \multirow{3}{*}{$\begin{array}{l}\text { No. of } \\
\text { cases }\end{array}$} & \multicolumn{6}{|c|}{ Tuberculin Reaction } \\
\hline & & \multicolumn{2}{|c|}{$1-5 \mathrm{~mm}$} & \multicolumn{2}{|c|}{$6-10 \mathrm{~mm}$} & \multicolumn{2}{|c|}{$>10 \mathrm{~mm}$} \\
\hline & & No. & $\%$ & No. & No. & $\%$ & No. \\
\hline Exposed & 68 & 34 & 50 & 8 & 12 & 26 & 38 \\
\hline \multirow[t]{2}{*}{ Not exposed } & 150 & 84 & 56 & 4 & 3 & 62 & 41 \\
\hline & 218 & 118 & & 12 & & 88 & \\
\hline \multicolumn{8}{|c|}{$\mathrm{X}^{2}-0.143 \mathrm{p}>0.05$ ( not significant) } \\
\hline
\end{tabular}

Table 5 showed among 218 children who were having contact in family with sputum positive adult of pulmonary tuberculosis, 88 children $(40 \%)$ had tuberculin reaction more than $10 \mathrm{~mm}$ indurations suggestive of tubercular infection. Among 88 children $21(23 \%)$ had tubercular disease and among disease $12(57 \%)$ children had pulmonary tuberculosis, 8 $(38 \%)$ children had tubercular lymphadenopathy and 1 children has intestinal tuberculosis.

\begin{tabular}{|c|c|c|c|c|}
\hline \multicolumn{5}{|c|}{ Table 5: Correlation of tuberculin reaction with clinical feature suggestive of tuberculosis } \\
\hline \multirow[t]{2}{*}{ Clinical feature } & \multirow[t]{2}{*}{ No. of cases } & \multicolumn{3}{|c|}{ Tuberculin test } \\
\hline & & 1-5mm & 6-10mm & $>10 \mathrm{~mm}$ \\
\hline Fever & 38 & 18 & & 20 \\
\hline Weight loss & 22 & 10 & & 12 \\
\hline Lymphadenopathy & 24 & 16 & 2 & 6 \\
\hline \multicolumn{5}{|c|}{ Correlation of tuberculin reaction with $x$-ray chest finding suggestive of tuberculosis } \\
\hline \multicolumn{5}{|l|}{ X-ray chest finding } \\
\hline Primary complex & & 0 & 0 & 0 \\
\hline Bronchopneumonia & & 2 & 0 & 2 \\
\hline Consolidation & & 4 & 0 & 4 \\
\hline Pleural effusion & & 0 & 0 & 2 \\
\hline Intestinal stricture & & & & 2 \\
\hline \multicolumn{5}{|c|}{ Incidence of tubercular disease } \\
\hline \multirow[t]{2}{*}{ Tubercular disease } & \multicolumn{2}{|c|}{ Incidence } & & \\
\hline & No.of cases & Percentage & & \\
\hline Pulmonary tuberculosis & 12 & 57 & & \\
\hline Lymph node tuberculosis & 8 & 38 & & \\
\hline Intestinal tuberculosis & 1 & 5 & & \\
\hline Total & 21 & & & \\
\hline
\end{tabular}

\section{Discussion}

Tuberculosis is continues to be important cause of morbidity and mortality in children worldwide. Childhood tuberculosis is a result of sputum positive pulmonary tuberculosis in adult. A child obtain infection by prolong close contact with an adult who has positive sputum $[11,12,13,14]$. Tuberculosis in children is paucibacillary and to large extent not associated with impact on the epidemiological situation in community due to small number of smear positive. Diagnosis of childhood tuberculosis is mainly based on clinical and radiological feature supplemented by a positive history of contact and tuberculin test.
Induration to tubercular antigen more than $10 \mathrm{~mm}$ more in 5-14 year of age group may be because of longer duration of contact with sputum positive adult but Singh $\mathrm{M}$ at el (2004) [15], M. Bansal at el observed high incidence of tubercular infection in younger age group. Similar to this study other authors also found prevalence of tuberculosis and tuberculin reactivity is high among lower socioeconomic and severely malnourished group[16,17].

In present study incidence is more common in less than 5 years of age group and male (statistically not 
significant), similar result were also seen in other study $[19,20,21]$.

We have observed that the size of indurations varied with nutritional status. This not coincides with hypothesis that severe malnutrition depresses hypersensitivity response to tuberculin test. Present study observed that, those children who were not vaccinated foe $\mathrm{BCG}$ had more positive reaction as compared to BCG vaccinated children reflecting infection is cause of positive reaction. Lifschitz at el \& Singh $\mathrm{M}$ at el also observed that more than $10 \mathrm{~mm}$ induration reflects positive tuberculin test for infection in children [22].

In this study we have not found any significant difference in transmission of infection between children exposed and not exposed to passive smoking because of about only one third of sputum positive adult male are smoker [10]. Singh M at el found positive correlation. Among children who had tubercular disease, pulmonary tuberculosis was more common than rest [15].

Our recommendation is routine screening of all children in contact with sputum positive adult of PTB and identify this group of child at high risk who should be screened if there of resources and time to screen all family contact.

\section{Funding: Nil \\ Conflict of interest: Nil \\ Permission from IRB: Yes}

\section{References}

1. Rieder HL. Contacts of tuberculosis patients in highincidence countries. Int J Tuberc Lung Dis. 2003 Dec;7(12 Suppl 3):S333-6.

2. Donald PR, Marais BJ, Barry CE 3rd. Age and the epidemiology and pathogenesis of tuberculosis. Lancet. 2010 May 29;375(9729):1852-4. doi: 10.1016/S0140-6736(10)60580-6. Epub 2010 May 18.

3. Centers for Disease Control and Prevention. Estimates for future global tuberculosis and mortality. JAMA. 1994 Mar 9;271(10):739, 741.

4. Charnace G de, Delacourt C. Diagnostic techniques in paediatric tuberculosis. Paediatr Respir Rev. 2001 Jun;2(2):120-6.
5. World Health Organization. Global Tuberculosis Report. Geneva: World Health Organization; 2013. Available at: http://www.who.int/tb/publications/global_report/en/ind ex.html.

6. WHO Global tuberculosis report, http://www.who.int/tb/publications/global_report/gtbr1

3_executive_summary.pdf.

7. World Health Organization. (2010). The global plan to stop TB 2011-2015: transforming the fight towards elimination of tuberculosis.

8. Bairwa M, Rajput M, Sachdeva S. Modified kuppuswamy's socioeconomic scale: social researcher should include updated income criteria, 2012 Indian J Community Med. 2013 Jul-Sep; 38(3): 185-186. doi: 10.4103/0970-0218.116358.

9 Fox GJ, Dobler CC, Marks GB. Active case finding in contacts of people with tuberculosis. Cochrane Database Syst Rev. 2011 Sep 7;(9):CD008477. doi: 10.1002/14651858.CD008477.pub2.

10. Altet MN, Alcaide J, Plans P et al. Passive smoking and the risk of pulmonary tuberculosis in children immediately following infection. A case control study. Tuber Lung Dis. 1996 Dec;77(6):537-44.

11. Newton SM, Brent AJ, Anderson S, et al. Paediatric tuberculosis. Lancet Infect Dis. 2008 Aug;8(8):498-510. doi: 10.1016/S1473-3099(08)70182-8.

12. Stop TB Partnership Childhood TB Subgroup, World Health Organization. Guidance for National Tuberculosis Programmes on the management of tuberculosis in children. Int J Tuberc Lung Dis. 2006 Nov;10(11):1205-11..

13. Salazar-Vergara RM, Sia IG, Tupasi TE, et al. Tuberculosis infection and disease in children living in households of Filipino patients with tuberculosis: a preliminary report. Int J Tuberc Lung Dis 2003;7(12 Suppl. 3):S494-500.

14. Vallejo JG, Ong LT, Starke JR. Clinical features, diagnosis, and treatment of tuberculosis in infants. Pediatrics. 1994 Jul;94(1):1-7. 
15. Singh M, Mynak ML, Kumar L, et al. Prevalence and risk factors for transmission of infection among children in household contact with adults having pulmonary tuberculosis. Arch Dis Child. 2005 Jun;90(6):624-8.

16. Schoeman JH,Westaway MS, Neethling A. The realationship between socioeconomic factors and pulmonary tuberculosis. Int J Epidemiol. 1991 Jun;20(2):435-40.

17. Jaganath D, Mupere E. Childhood tuberculosis and malnutrition. J Infect Dis. 2012;206(12):1809-1815.

18. Kumar, RA, Saran, M, Verma, BL, Srivastava, RN. Pulmonary tuberculosis among contacts of patients with tuberculosis in an urban Indian population. $\mathbf{J}$ Epidemiol Community Health. 1984 Sep;38(3):253-8.
19. Bhakoo, ON, Gupte SP. Tuberculosis in children. Indian J Pediatr. 1969 Mar;36(254):65-70.

20. Caldeira, Zelina MR, Clemax C. Sant'Anna, and Miguel Abdom Aidé. Tuberculosis contact tracing among children and adolescents, Brazil. Paediatr Respir Rev. 2001 Jun;2(2):120-6.

21. Fuimaono A, Vince J. Screening contacts of children with tuberculosis: an important and worthwhile part of case management. P N G Med J. 1997 Jun;40(2):69-73.

22. Lifschitz, Martin. The value of the tuberculin skin test as a screening test for tuberculosis among BCGvaccinated children. Pediatrics. 1965 Oct;36(4):624-7.

\section{How to cite this article?}

Beck P, Kurrey VK, Dawale P . Prevalence of tuberculosis in children of sputum positive adult of pulmonary tuberculosis living in same household. Int J Med Res Rev 2015;3(6):608-613. doi: 10.17511/ijmrr.2015.i6.118. 